\title{
ỨNG DỤNG DŨ LIỆU VIỄN THÁM RADAR TRONG XÁC ĐỊNH SINH KHỐI LỚP PHỦ RỪNG TẠI VIỆT NAM
}

\author{
TRẦN TUẤN NGỌC \\ NGUYẼ̃N THANH NGA \\ Cục Viễn Thám Quốc gia
}

\section{Tóm tắt:}

Biến đổi khí hậu đang diễn biến phức tạp và ảnh hưởng ngày càng lớn đến mọi mặt kinh tế, xã hội của loài người. Để giảm nhẹ biến đổi khí hậu thì việc bảo tồn và phát triển rừng có ý nghĩa hết sức to lớn. Để có thể bảo tồn và phát triển rừng thì các số liệu về rừng trong đó có sinh khối rừng có ý nghĩa hết sức quan trọng. Trong bài báo này tác giả giới thiệu phương pháp tính sinh khối rừng trên mặt đất dưa trên giá trị tán xạ ngược trên ảnh radar. Kết quả thử nghiệm tính sinh khối rừng tại tỉnh Hòa Bình là khả quan chứng tỏ đây là phương pháp rất có tiềm năng trong tính sinh khối rừng tại Việt Nam.

\section{1. Đặt vấn đề}

Lịch sử phát triển của loài người gắn liền với rừng và sử dụng rừng. Rừng là nguồn cung cấp nguyên liệu thô cho xây dựng, giao thông, là nguồn thực phẩm cho con người và khi bị chặt phá đất rừng trở thành tài nguyên đất cho canh tác nông nghiệp và cho phát triển đồ thị [1]. Rừng ngày nay đang bị suy giảm, việc suy thoái rừng và chặt phá rừng kéo theo nhiều hệ lụy cho con người và sự phát triển bền vững của xã hội loài người. Chặt phá rừng không chỉ là một trong các tác nhân chính gây ra hiện tượng nóng lên của trái đất thông qua tăng khí thải nhà kính trong khí quyển mà còn làm ảnh hưởng nghiêm trọng đến chu trình tuần hoàn của nước, tăng tần xuất cũng như cường độ lũ lụt, suy kiệt tầng trữ nước, làm thoái hóa đất và dẫn đến sự tuyệt chủng của một số loài thực vật và động vật có môi trường sống là rừng [2].

Với tầm quan trọng của rừng thì việc bảo vệ rừng đang là vấn đề hết sức cấp thiết trên thế giới. Tổ chức Nông Lương Liên hợp quốc $(\mathrm{FAO})$ cho rằng thông tin chính xác và đầy đủ về rừng là rất quan trọng để có thể quản lý và phát triển rừng một cách hiệu quả [1]. Không chỉ có FAO quan tâm đến các số liệu về rừng, Công ước khung của Liên hiệp quốc về biến đổi khí hậu (FCCC) đề cập đến tầm quan trọng của rừng và hết sức quan tâm đến số liệu về rừng đặc biệt là sinh khối rừng, số liệu liên quan trực tiếp đến hàm lượng các bon chứa trong rừng[3].

Đối với nước ta, rừng có vai trò hết sức quan trọng trong công cuộc phát triển kinh tế xã hội và bảo vệ môi trường. Theo tính toán chính thống thì rừng đóng góp trực tiếp vào $1 \%$ GDP quốc gia, nhưng điều quan trọng hơn, rừng là nơi sinh sống của 25 triệu người với nhiều người thuộc đồng bào dân tộc ít người [4]. Để quản lý, bảo vệ và phát triển rừng, nước ta tiến hành điều tra đánh giá rừng theo chu kỳ năm năm [4]. Việc điều tra, đánh giá rừng theo chu kỳ 5 năm vẫn chưa thỏa mãn nhu cầu của các nhà quản lý, do thời gian điều tra khá dài nên có sự sai lệch giữa báo cáo với tình hình thực tế của hiện trạng rừng do việc khai thác và phát triển rừng trong thời gian diễn ra điều tra nhất là với rừng trồng, đối 
tượng thường được thu hoạch sau khi trồng từ 5 đến 7 năm. Tuy nhiên, để nâng cao tần xuất điều tra, đánh giá hiện trạng rừng là vấn đề hết sức khó khăn khi sử dụng dữ liệu viễn thám quang học, loại dữ liệu mà việc chụp ảnh phụ thuộc vào điều kiện thời tiết.

Để khắc phục hạn chế về nguồn dữ liệu trong điều tra đánh giá rừng, hiện nay trên thế giới đã có nhiều nghiên cứu ứng dữ liệu viễn thám siêu cao tần hay còn gọi là viễn thám radar [5-6]. Dữ liệu viễn thám radar có lợi thế so với viễn thám quang học đó là việc chụp ảnh không phụ thuộc vào điều kiện thời tiết nên có khả năng chụp ảnh cho diện tích lớn trong thời gian ngắn. Bên cạnh đó, việc xác định trực tiếp thông số sinh khối rừng thông qua ảnh radar cũng là một trong các lợi thế so với sử dụng dữ liệu viễn thám quang học.

Ứng dụng dữ liệu RADAR trong xác định sinh khối rừng tuy không phải là vấn đề mới đối với thế giới, tuy nhiên, các nghiên cứu trên thế giới cho đến nay tập trung chủ yếu vào rừng phía bắc (boreal forest) với chủng loài thông. Hơn nữa, độ chính xác xác định sinh khối rừng bằng dữ liệu ảnh RADAR phụ thuộc rất nhiều vào các yếu tố như trữ lượng rừng, đặc điểm sinh thái rừng, các điều kiện môi trường [7-8]. Do vậy, để áp dụng công nghệ này cho việc xác định sinh khối rừng ở Việt Nam cần có các nghiên cứu về cơ sở khoa học, phương pháp luận cũng như tiến hành thử nghiệm để kiểm chứng. Chỉ trên nền tảng như vậy thì mới có thể đưa ra được các kết luật xác đáng về khả năng ứng dụng của công nghệ trong điều kiện cụ thể ở Việt Nam.

\section{Tổng quan ứng dụng viễn thám trong xác định sinh khối lớp phủ rừng trên thế giới}

Từ những năm 90 của thế kỷ trước, nhiều công trình nghiên cứu khoa học đã được công bố chứng tỏ tiềm năng của viễn thám radar trong việc xác định sinh khối trên mặt đất của lớp phủ rừng. Với mối quan tâm ngày càng cao của xã hội đến thông tin về sinh khối rừng thì việc ứng dụng dữ liệu viễn thám radar trong xác định sinh khối rừng trên mặt đất đã và đang được các nhà khoa học nghiên cứu và phát triển mạnh mẽ trong thời gian gần đây [9-12].

Đối với các ứng dụng về thành lập bản đồ sinh khối rừng, việc khai thác nguồn dữ liệu radar cho tới nay được thực hiện bằng hai phương pháp chính đó là phương pháp trực tiếp và gián tiếp [13]. Phương pháp trực tiếp thiết lập mối quan hệ giữa sinh khối và tín hiệu radar phản hồi trên cơ sở cường độ tán xạ ngược (backscatter) hoặc hệ số tương quan (coherence). Trong khi đó, phương pháp gián tiếp ước tính sinh khối dựa trên việc sử dụng tham số chiều cao cây kết hợp với việc sử dụng phương trình sinh trưởng.

a. Phương pháp ước tính sinh khối dựa trên cường độ tán xạ

Từ những năm đầu của thập kỷ 1990, mối quan hệ giữa tán xạ ngược của sóng siêu cao tần và tổng sinh khối trên mặt đất đã được nghiên cứu một cách rộng khắp tại nhiều khu vực thử nghiệm khác nhau. Phương pháp này dựa trên cơ sở vật lý đó là sóng radar với bước sóng dài có khả năng xuyên vào sâu trong tán lá và tương tác với các thành phần của cây như lá, cuống cành và thân cây. Khi tương tác với các thành phần khác nhau của cây với hằng số điện môi tương đối khác nhau sẽ làm thay đổi thuộc tính của tia phản hồi về cường độ và phân cực, những thay đổi này tương quan với thuộc tính của cây hay nói cụ thể hơn là tia phản hồi mang thông tin về sinh khối của cây nhờ đó có thể tính được sinh khối của lớp phủ thực vật trên mặt đất [14].

b. Phương pháp ước tính sinh khối dựa trên ảnh tương quan

Phương pháp này sử dụng giá trị tương 
quan giữa hai ảnh SAR được thu nhận cách nhau một khoảng thời gian ngắn sử dụng kỹ thuật giao thoa. Việc tính toán sinh khối trên mặt đất lớp phủ rừng dựa trên giả thiết, thực vật với sinh khối lớn có sự ổn định cao và ít bị tác động của môi trường (gió, mưa) nên giá trị tương quan cao trên ảnh hơn so với thực vật có sinh khối thấp hơn. Nghiên cứu sinh khối trên mặt đất của lớp phủ rừng sử dụng giá trị tương quan của cặp ảnh radar được thực hiện nở rộ vào đầu những năm 2000 khi vệ tinh ERS1/2 của ESA được phóng lên cho khả năng chụp ảnh theo cấu hình Tandem và đã có những thành tựu nhất định đối với rừng phương bắc, cây họ thông. Nhiều nghiên cứu đã chứng tỏ, sử dụng trị tương quan có thể nghiên cứu sinh khối tới 300 t/ha [15-16].

c. Phương pháp ước tính sinh khối dựa trên trị đo pha

Kỹ thuật InSAR dựa trên việc khai thác vân giao thoa của hai sóng điện từ trường để ước tính độ cao của tâm pha tán xạ. Vị trí của tâm pha tán xạ phụ thuộc vào cấu trúc của thảm thực vật, các cơ chế tán xạ và tính chất của bộ cảm. Đối với khu vực có thảm thực vật rừng, tâm pha tán xạ là tổng hợp của tất cả các tín hiệu phản hồi từ một tập hợp lớn các đối tượng tán xạ bao gồm lá, cành, thân cây và mặt đất trên diện tích được xác định bởi kích thước một phần tử ảnh. Tâm phát xạ thường quy định bởi các đối tượng tương tác mạnh nhất với sóng radar và phụ thuộc vào tần số, sự phân cực, góc tới, cũng như độ dày của tán và mật độ rừng. Kỹ thuật giao thoa có thể được dùng để ước tính chiều cao tán rừng do trị đo pha giao thoa liên quan đến tâm tán xạ, mà nếu lựa chọn dải tần và phân cực một cách thích hợp, sẽ bao gồm cả độ cao địa hình và chiều cao của tán rừng.

\section{d. Lựa chọn phương pháp}

Bảng 1 cho thấy việc tính sinh khối rừng trên mặt đất sử dụng trị đo pha và giá trị tương quan của các cảnh ảnh là tương đối tương đồng do thực chất cả hai phương pháp này đều sử dụng công nghệ radar giao thoa. Để có cặp ảnh có giá trị tương quan cao, ảnh phải được chụp với khác biệt về thời gian đến tối thiểu, và thông số quỹ đạo vệ tinh có sự tương đồng hết sức chặt chẽ giữa hai lần chụp.

Bảng 1: So sánh phương pháp xác định sinh khối bằng dữ liệu radar

\begin{tabular}{|c|c|c|c|}
\hline \multirow{2}{*}{$\begin{array}{c}\text { Các yếu tố ảnh hưởng đến } \\
\text { kết quả }\end{array}$} & \multicolumn{3}{|c|}{ Phương pháp } \\
\cline { 2 - 4 } & Giá trị tán xạ & Hệ số tương quan & Trị đo pha \\
\hline Ngưỡng bão hòa (kênh L) & 150 t/ha & 200 t/ha & 300 t/ha \\
\hline Thu thập dữ liệu & Đơn & Lặp theo chu kỳ & Lặp theo chu kỳ \\
\hline Yêu cầu quỹ đạo & Bình thường & Chính xác cao & Chính xác cao \\
\hline Nhiễu pha & Không phụ thuộc & Phụ thuộc & Phụ thuộc \\
\hline Điều kiện cung cấp dữ liệu & Không hạn chế & Hạn chế & Hạn chế \\
\hline Địa hình & Phụ thuộc & Phụ thuộc & Phụ thuộc \\
\hline Sự dịch chuyển của địa hình & Ít phụ thuộc & Phụ thuộc & Phụ thuộc \\
\hline Điều kiện thời tiết & Ít phụ thuộc & Phụ thuộc & Phụ thuộc \\
\hline Khí quyển & Ít phụ thuộc & Phụ thuộc & Phụ thuộc \\
\hline
\end{tabular}


Trong khi đó, phương pháp sử dụng trị tán xạ của ảnh có các yêu cầu thuận tiện hơn rất nhiều cho người sử dụng. Trị tán xạ trên ảnh cũng phụ thuộc không nhiều vào điều kiện thời tiết nên có thể thu thập ảnh dễ dàng, ngoài ra việc cung cấp ảnh cũng không có bất kỳ hạn chế nào.

Điều bất lợi nhất của phương pháp này so với hai phương pháp còn lại là ngưỡng bão hòa của giá trị tán xạ với sinh khối rừng nhỏ hơn. Tuy nhiên với sinh khối rừng trên mặt đất không lớn của Việt Nam $(70$ m³/ha so với $110 \mathrm{~m}^{3} / \mathrm{ha}$ ) thì bất lợi này cũng không ảnh hưởng nhiều đến hầu hết diện tích rừng của nước ta nếu sử dụng phương pháp này để xác định sinh khối rừng trên mặt đất.

Như vậy, có thể thấy để tính sinh khối rừng trên mặt đất ở Việt Nam sử dụng giá trị tán xạ ngược trên ảnh radar có nhiều ưu điểm hơn so với sử dụng trị tương quan trên ảnh cũng như trị đo pha.

\section{Thực nghiệm tính sinh khối rừng trên mặt đất tỉnh Hòa Bình.}

a. Dũ liệu sử dụng

Trong thực nghiệm này sử dụng 02 cảnh ảnh ALOS PALSAR ở chế độ chụp strip mode. Bảng 2 Thể hiện các thông số kỹ thuật của dữ liệu ALOS PALSAR sử dụng. (Xem bảng 2)

Để hồi quy với giá trị tán xạ ngược trên ảnh, 83 ô tiêu chuẩn được sử dụng trong công tác thử nghiệm tính sinh khối trên mặt đất lớp phủ rừng tỉnh Hòa Bình. Hình 1 cho thấy các ô tiêu chuẩn được bố trí trải khắp trên toàn tỉnh, tuy nhiên phía đông của tỉnh nơi thuận tiện giao thông có số điểm nhiều hơn. (Xem hình 1)

Bảng 2: Thông số kỹ thuật của ảnh ALOS PALSAR sử dụng

\begin{tabular}{|c|c|c|c|c|c|c|}
\hline TT & Ngày chụp & Góc chụp & Quỹ đạo & Phân cực & Khuôn dạng & Mã hóa \\
\hline 1 & $20 / 06 / 2007$ & $34.3^{0}$ & A & HH/VV & CEOS & 16 bit \\
\hline 2 & $07 / 07 / 2007$ & $34.3^{0}$ & A & HH/VV & CEOS & 16 bit \\
\hline
\end{tabular}

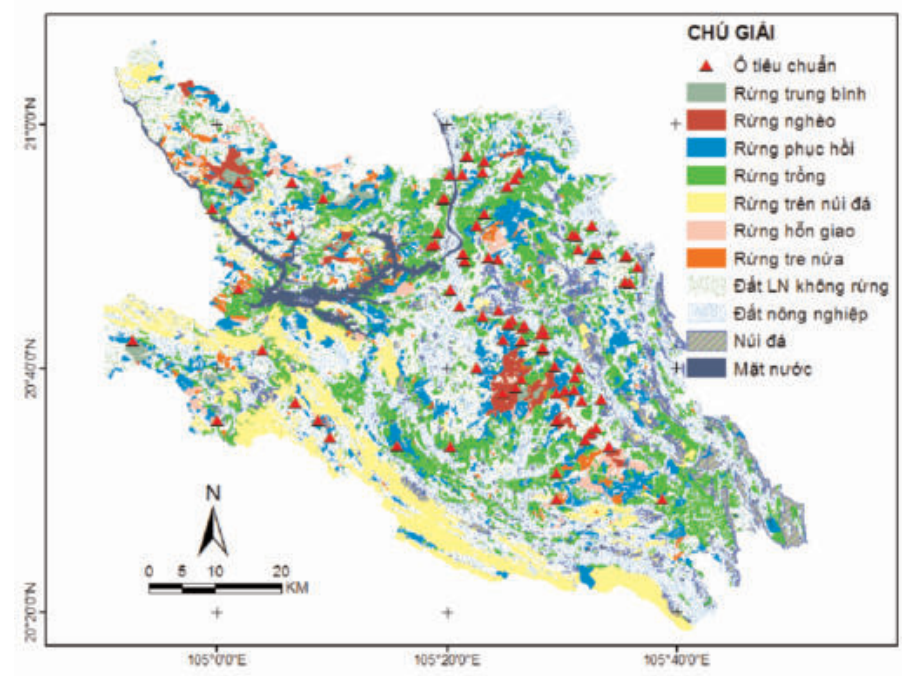

Hình 1: Sơ đồ các ô tiêu chuẩn 
b) Hồi quy giá trị tán xạ trên ảnh với sinh khối rừng trên mặt đất

Giá trị tán xạ ngược trên ảnh tại vị trí tương ứng với 30 ô tiêu chuẩn được sử dụng để hồi quy với sinh khối rừng trên mặt đất sử dụng hàm đa tuyến. Bảng 3 thể hiện kết quả hồi quy đa tuyến đối với giá trị tán xạ trên ảnh ALOS PALSAR và sinh khối rừng tại các ô tiêu chuẩn đo ngoài thực địa. Bảng 3 cho thấy, việc hồi quy sử dụng trị đo tán xạ cả hai phân cực $H H$ và $H V$ cải thiện đáng kể kết quả hồi quy với giá trị xác định $\mathrm{R}^{2}$ tăng từ 0.808 đối với việc sử dụng trị đo tán xạ ngược phân cực HH lên 0.918 khi sử dụng trị đo từ cả hai phân cực.

\section{c) Tính sinh khối}

Sau khi hối quy giá trị tán xạ ngược trên ảnh và giá trị sinh khối rừng trên mặt đất ô tiêu chuẩn, phương trình thu được sử dụng để tính sinh khối trên mặt đất rừng tỉnh Hòa Bình từ giá trị tán xạ ngược trên ảnh ALOS PALSAR như sau:

$B=7.878 \times X(H V)_{i, j}+4.940 \times Y(H H)_{i, j}+205.392$

Trong đó:

- B là giá trị sinh khối (tấn/ha);

- X (HV) là trị tán xạ phân cực HV trên ảnh $(\mathrm{Db})$;

- Y $(\mathrm{HH})$ là trị tán xạ phân cực $\mathrm{HH}$ trên ảnh (Db);

- i, j là số thứ tự hàng và cột trên ảnh.

Hình 2 thể hiện kết quả tính sinh khối rừng trên mặt đất sử dụng giá trị tán xạ trên ảnh radar sử dụng công thức 1 .

Bảng 3: Hồi quy đa tuyến đối với dữ liệu ALOS PALSAR

\begin{tabular}{|c|c|c|c|c|}
\hline Trị đo sử dụng & R2 & F & F tới hạn & Sai số chuẩn \\
\hline Phân cực HH và HV & 0.918 & 151.739 & 0.000 & 17.339 \\
\hline Phân cực HV & 0.847 & 155.434 & 0.000 & 23.274 \\
\hline Phân cực HH & 0.808 & 117.461 & 0.000 & 26.136 \\
\hline
\end{tabular}

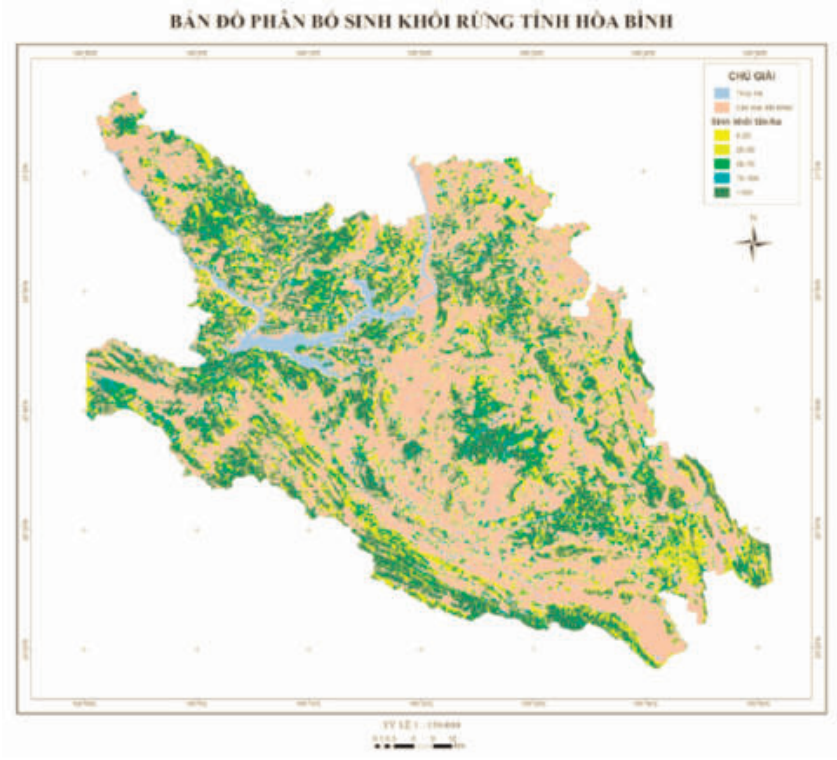

Hình 2: Bản đồ sinh khối trên mặt đất rừng tỉnh Hòa Bình 
Để đánh giá kết quả tính sinh khối, giá trị sinh khối rừng trên mặt đất của các ô tiêu chuẩn không sử dụng trong tính toán hồi quy được sử dụng để so sánh với kết quả tính sinh khối dựa trên giá trị tán xạ trên ảnh. Bảng 3 so sánh giá trị sinh khối trên mặt đất tại vị trí các ô tiêu chuẩn có giá trị sinh khối lớn hơn 15 tấn/ha. Bảng cho kết quả khác khả quan với sai số trung phương khoảng 6.5 tấn/ha. Tỷ lệ về sai số tính sinh khối với sinh khối rừng có sai số độ lệch chuẩn là khoảng $23 \%$, hay nói cách khác tính sinh khối có thể cho độ chính xác tới $77 \%$. (Xem bảng 4)

\section{Kết Iuận}

Kết quả tính sinh khối rừng trên mặt đất tỉnh Hòa Bình sử dụng ảnh viền thám radar có độ chính xác cao với sai số trung phương khoảng 6.5 tấn/ha và độ lệch chuẩn nếu tính theo tỷ lệ với sinh khối rừng là $23 \%$. Kết quả này chứng tỏ, sử dụng giá trị tán xạ trên ảnh radar để tính sinh khối rừng trên măt đất là rất khả quan và có nhiều tiềm năng để sử dụng trên thực tế.

Tuy nhiên rừng tỉnh Hòa Bình chỉ đại diện cho một trong năm loại sinh thái rừng ở Việt Nam đó là rừng thường xanh trên núi đá vôii, cần ứng dụng tính sinh khối sử dụng ảnh radar đối với các hệ sinh thái rừng khác. $\bigcirc$

\section{Tài liệu tham khảo}

[1]. FAO., State of the World's Forests, s.o.w. forest, Editor. 2012, FAO: ROME.

[2]. Musselman. R. C. and Fox. D. G., A Review of the Role of Temperate Forests in the Global CO2 Balance., in Journal of the Air and Waste Management Association. 2012, Taylor \& Francis: London.

[3]. Framework Convention on Climate Change, Report of the Conference of the Parties on its fifteenth session, held in Copenhagen from 7 to 19 December 2009, in Framework Convention on Climate Change,, D. CP15.pdf, Editor. 2009, United Nation: Copenhagen.

[4]. Bộ Nông nghiệp và Phát triển Nông thôn. (2011) Báo cáo tiến độ ngành Lâm nghiệp 2006 - 2010.

[5]. Beaudoin, A., et al., Retrieval of
Forest Biomass from SAR Data. International Journal of Remote Sensing, 1994. 15(14): p. 2777-2796.

[6]. Askne. J. and Santoro. M., Boreal forest sterm volum estimation from multitemporal C-band Insar observation. 2008.

[7]. Austine, J.M., B.G. Mackey, and K.P. Van Niel, Estimating forest biomass using satellite radar: an exploratary study in a temprate Australia Eucaliptus forest. Forest ecology management, 2003. 176(1-3): p. 575-583.

[8]. Balzter, H., C.S. Rowland, and P. Saich, Forestry Canopy Height and Carbon Estimation at Monks Wood National Nature Reserve, UK, Using Dual-wavelength SAR Interferometry. Remote Sensing of Environment, 2007. 108(3): p. 224-239.

[9]. Beaudoin, A., et al., Retrieval of forest Biomass form SAR data. International Journal of Remote Sensing, 1994. 15(14): p. $2777-2796$.

[10]. Rauste, T.H., et al., Radar-based Forest Biomass Estimation. International Journal of Remote Sensing, 1994. 15(14): p. 2797-2808.

[11]. Letoan, T., A. Beaudoin, and D. Guyon, Relating forest biomass to SAR data. IEEE Transactions on Geoscience and Remote Sensing, 1992. 30: p. 403-411.

[12]. Imhoff, M.L., et al., BioSar (TM): an inexpensive airborne VHF multiband SAR system for vegetation biomass measurement. IEEE Transactions on Geoscience and Remote Sensing, 2000. 38: p. 14581462.

[13]. Koch, B., Status and Future of Laser Scanning, SAR and Hyperspectral Remote Sensing Data for Forest Biomass Assessment. ISPRS Journal of Photogrammetry and Remote Sensing, 2010. 65: p. 581-590.

[14]. Ulaby, F.T., R.K. Moore, and A.K. Fung, Microwave Remote Sensing- Active and Passive. 1986, Dedham, MA: Artech House Inc.

[15]. Fransson, J.E., Stem volume estimation in boreal forests using ERS1/2 coherence and SPOT XS optical data. International Journal of Remote Sensing, 
Bảng 4: So sánh sinh khối tính từ ảnh với sinh khối ô tiêu chuẩn với sinh khối rừng trên mặt đất lớn hơn 15 tấn/ha

\begin{tabular}{|c|c|c|c|c|c|c|}
\hline Tên điếm & Tọa độ X & Tọa độ Y & Sinh khối đo & Sinh khối tính & Chênh GT & Tỷ lệ \\
\hline OTC_29 & 2314542 & 537146 & 17.700 & 22.900 & 5.200 & 29.379 \\
\hline OTC_30 & 2317475 & 537838 & 26.700 & 32.786 & 6.086 & 22.795 \\
\hline OTC 31 & 2317438 & 537905 & 27.920 & 31.223 & 3.303 & 11.830 \\
\hline OTC_32 & 2316649 & 540480 & 49.640 & 56.546 & 6.906 & 13.913 \\
\hline OTC_34 & 2314833 & 545749 & 24.480 & 26.899 & 2.419 & 9.881 \\
\hline OTC_36 & 2312797 & 543995 & 30.120 & 27.932 & -2.188 & -7.263 \\
\hline OTC_39 & 2301823 & 542554 & 20.580 & 11.930 & -8.650 & -42.029 \\
\hline OTC_42 & 2311017 & 534491 & 28.960 & 24.089 & -4.871 & -16.821 \\
\hline OTC_43 & 2314549 & 535256 & 32.660 & 34.288 & 1.628 & 4.985 \\
\hline OTC_46 & 2305840 & 533434 & 26.650 & 32.752 & 6.102 & 22.895 \\
\hline OTC_47 & 2301478 & 537576 & 23.300 & 18.227 & -5.073 & -21.771 \\
\hline OTC_49 & 2291250 & 549359 & 56.070 & 59.884 & 3.814 & 6.802 \\
\hline OTC_50 & 2290471 & 549026 & 18.100 & 27.557 & 9.457 & 52.249 \\
\hline OTC_52 & 2275631 & 556650 & 24.020 & 18.725 & -5.295 & -22.043 \\
\hline OTC_54 & 2276226 & 557374 & 24.110 & 19.971 & -4.139 & -17.167 \\
\hline OTC_55 & 2274431 & 555700 & 38.680 & 33.032 & -5.648 & -14.603 \\
\hline OTC_60 & 2285335 & 554725 & 21.290 & 36.779 & 15.489 & 72.751 \\
\hline OTC_61 & 2283952 & 554172 & 44.170 & 41.443 & -2.727 & -6.175 \\
\hline OTC_62 & 2292560 & 544748 & 18.800 & 24.300 & 5.500 & 29.255 \\
\hline OTC_63 & 2294053 & 542678 & 26.670 & 22.157 & -4.513 & -16.922 \\
\hline OTC_64 & 2293208 & 540278 & 55.900 & 61.528 & 5.628 & 10.067 \\
\hline OTC_65 & 2285647 & 551163 & 17.000 & 11.854 & -5.146 & -30.271 \\
\hline OTC_71 & 2291422 & 546257 & 45.080 & 56.654 & 11.574 & 25.674 \\
\hline OTC_72 & 2291730 & 546488 & 18.100 & 24.300 & 6.200 & 34.254 \\
\hline OTC_73 & 2291861 & 544293 & 65.110 & 79.013 & 13.903 & 21.353 \\
\hline OTC_74 & 2292013 & 544053 & 36.140 & 44.108 & 7.968 & 22.048 \\
\hline OTC_75 & 2301951 & 556659 & 45.720 & 46.845 & 1.125 & 2.461 \\
\hline OTC_76 & 2302640 & 557641 & 34.420 & 41.246 & 6.826 & 19.832 \\
\hline OTC_77 & 2302620 & 557205 & 20.430 & 27.363 & 6.933 & 33.934 \\
\hline OTC_82 & 2302179 & 561779 & 21.830 & 26.254 & 4.424 & 20.268 \\
\hline OTC_83 & 2302387 & 562010 & 27.840 & 35.280 & 7.440 & 26.726 \\
\hline OTC_84 & 2298170 & 562570 & 24.850 & 31.755 & 6.905 & 27.789 \\
\hline OTC_86 & 2300581 & 563643 & 23.940 & 29.655 & 5.715 & 23.873 \\
\hline PP_05_MT & 2277437 & 551385 & 80.000 & 78.635 & -1.365 & -1.706 \\
\hline PP_09_DR & 2309459 & 499385 & 61.000 & 67.168 & 6.168 & 10.111 \\
\hline PP_10_BS & 2277449 & 515412 & 58.000 & 62.410 & 4.410 & 7.604 \\
\hline PP_12_DL & 2273514 & 535312 & 48.330 & 45.135 & -3.195 & -6.612 \\
\hline PP_19_LV & 2274907 & 517195 & 128.000 & 135.242 & 7.242 & 5.658 \\
\hline PP_20_NL & 2280152 & 511970 & 34.000 & 24.938 & -9.062 & -26.653 \\
\hline PP_21_TD & 2288100 & 506955 & 160.000 & 143.285 & -16.715 & -10.447 \\
\hline DT_10 & 2311063 & 516184 & 217.000 & 198.914 & -18.086 & -8.335 \\
\hline \multicolumn{5}{|l|}{$\overline{\text { STDV }}$} & 7.490 & 23.2536 \\
\hline \multicolumn{5}{|l|}{ RMSE } & 6.524 & \\
\hline
\end{tabular}


2001. 25: p. 2777-2791.

[16]. Le Toan, T., et al., On the Relationship Between Radar Measurements and Forest Structure and
Biomass. Proceedings of the 3th International Symposium on Retrieval of Bio- and Geo-physical Parameters from SAR data for Land Application, Sheffield, UK, 2001.O

\title{
Summary
}

Application of radar remote sensing data in determining the forest biomass in Vietnam

Tran Tuan Ngoc, Nguyen Thanh Nga

Vietnam Remote Sensing Center

Climate change has severe impacted to human socio-economic. Forest plays critical role in the works of climate change reduction and mitigation. To protect the forests, the forest investigation data including the forest biomass is very important. This paper introduces the works of forest above ground estimation using radar backscattering data. The experiment calculating forest above ground biomass in Hoa Binh province has significant result with the RMSE of 6.7 ton/ha, which improve that radar backscattering data could be the potential data for forest above biomass estimation in Vietnam. $O$

Ngày nhận bài: 06/02/2014.

\section{SO SÁNH LƯợNG HƠI NƯớC.....}

\author{
(Tiếp theo trang 28)
}

[7]. Ha-Taek KWON, (2007), "Comparison of Precipitable Water Derived from GroundBased GPS Measurements with Radiosonde Observation over the Korean Peninsula", Journal of the Meteorological Society of Japan, Vol. 85, No. 6, pp. 733-746.

[8]. Paul Tregoning, (1998), "Accuracy of absolute precipitable water vapor estimates from GPS observations", Journal of Geophysical Research, Vol.103, No.D22, pp. 28,70128,710. O

\section{Summary}

Comparison of PWV values derived by GNSS and by radiosonde at Tan Son Hoa station, Hochiminh City

Huynh Nguyen Dinh Quoc, Ho Chi Minh City University of Natural Resources and Environment

Nguyen Ngoc Lau, Hochiminh City University of Technology

Precipitable water vapor (PWV) in the atmosphere is essential for weather forecast. Currently, correct determination of PWV is a big concern to those talking interest in hydrometeorology. In this paper, we present the algorithms for determining PWV and then compare between PWV derived from radiosonde observation data and PWV derived from GPS data at Tan Son Hoa Station, Ho Chi Minh City. The deviations between the two PWV values in this study, are less than $1.2 \mathrm{~mm}$. In addition, PWV values changed in accordance with changes of weather on the surveying days. $O$

Ngày nhận bài: 14/12/2013. 